\title{
Enhancing the Infrared Photoresponse of Silicon by Controlling the Fermi Level Location within an Impurity Band
}

\section{Citation}

Simmons, Christie B., Austin J. Akey, Jonathan P. Mailoa, Daniel Recht, Michael J. Aziz, and Tonio Buonassisi. 2014. Enhancing the Infrared Photoresponse of Silicon by Controlling the Fermi Level Location Within an Impurity Band. Advanced Functional Materials 24, no. 19: 28522858.

\section{Published Version}

doi:10.1002/adfm.201303820

\section{Permanent link}

http://nrs.harvard.edu/urn-3:HUL.InstRepos:12992314

\section{Terms of Use}

This article was downloaded from Harvard University's DASH repository, and is made available under the terms and conditions applicable to Open Access Policy Articles, as set forth at http:// nrs.harvard.edu/urn-3:HUL.InstRepos:dash.current.terms-of-use\#OAP

\section{Share Your Story}

The Harvard community has made this article openly available.

Please share how this access benefits you. Submit a story.

Accessibility 


\title{
Enhancing the Infrared Photoresponse of Silicon by Controlling the Fermi Level Location within an Impurity Band
}

\author{
C. B. Simmons*, Austin J. Akey, Jonathan P. Mailoa, \\ Daniel Recht, Michael J. Aziz, and Tonio Buonassisi
}

\begin{abstract}
Dr. C. B. Simmons, Dr. A. J. Akey, J. P. Mailoa, Prof. T. Buonassisi
Massachusetts Institute of Technology, Cambridge, Massachusetts 02139, USA

E-mail: Christie.simmons@gmail.com

Dr. D. Recht, Prof. M. J. Aziz

Harvard School of Engineering and Applied Sciences, Cambridge, Massachusetts 02138, USA
\end{abstract}

Keywords: impurity band; defect engineering; compensated semiconductor; extrinsic photoconductivity; pulsed laser melting

Strong absorption of sub-band gap radiation by an impurity band has recently been demonstrated in silicon supersaturated with chalcogen impurities. However, despite the enhanced absorption in this material, the transformation of infrared radiation into an electrical signal via extrinsic photoconductivity - the critical performance requirement for many optoelectronic applications - has only been reported at low temperature because thermal impurity ionization overwhelms photoionization at room temperature. Here, we use dopant compensation to manipulate the optical and electronic properties and thereby improve the room-temperature infrared photoresponse. We fabricate silicon co-doped with boron and sulfur using ion implantation and nanosecond pulsed laser melting to achieve supersaturated sulfur concentrations and a matched boron distribution. The location of the Fermi level within the sulfur-induced impurity band is controlled by tuning the acceptor-to-donor ratio, and through this dopant compensation, we demonstrate three orders of magnitude improvement in infrared detection at $1550 \mathrm{~nm}$ due to a reduction in the background carrier concentration. 


\section{INTRODUCTION}

Silicon is the most economical, technologically sophisticated, and has the highest crystal quality of any semiconductor material, but its optoelectronic applications are limited to the visible and near-infrared spectral range due to its $1.12 \mathrm{eV}$ band gap $(\lambda=1110 \mathrm{~nm})$. Extending the photoresponse into the short-wavelength infrared (SWIR) regime (0.89 to $0.41 \mathrm{eV}$ or 1400 to $3000 \mathrm{~nm}$ ) has been a topic of great interest because it has the potential to revolutionize silicon-based optoelectronics, enabling the development of CMOS-compatible photonic systems that can integrate optical and electronic functions on a single chip. ${ }^{1,2}$

The introduction of dopant impurities or crystal lattice point defects can result in photoresponse at sub-band gap wavelengths due to defect-mediated extrinsic carrier generation. The detectivity of extrinsic photoconductive detectors depends on the ratio of optical carrier generation to thermal carrier generation. Traditionally, extrinsic silicon photodetectors have been limited by either high thermal impurity ionization or low optical carrier generation due to low absorption of sub-band gap radiation. Commonly used group III or V dopants (B, $\mathrm{Al}, \mathrm{Ga}, \mathrm{P}, \mathrm{As}$ and $\mathrm{Sb}$ ) have high solubilities in solid silicon, but these impurities introduce shallow defect states that are thermally ionized at room-temperature, so extremely low operating temperatures (below $\sim 40 \mathrm{~K}$ ) are required for their use in extrinsic photodetectors. ${ }^{1,3}$ Alternatively, lattice defects, which can be introduced by bombardment with $\mathrm{Si}^{+}$ions, $\mathrm{Ar}^{+}$ ions, protons, or neutrons, can be optically active without producing thermally generated free carriers, but they typically result in relatively low sub-band gap absorption coefficients, $\alpha \sim 0.5-50 \mathrm{~cm}^{-1}{ }^{4-8}$

The operation temperature of impurity doped extrinsic photodetectors can be increased by using deep-level impurities, which requirer higher temperatures for thermal ionization. ${ }^{9}$ Deep-level impurities, however, have low solubilities in silicon (max impurity concentration $\left.N_{I} \sim 10^{16}-10^{18} \mathrm{~cm}^{-3}\right),{ }^{10}$ which typically limits $\alpha=\sigma N_{I}$ to $\sim 10 \mathrm{~cm}^{-1}$, where $\sigma$, the photoionization cross section, is approximately $10^{-16} \mathrm{~cm}^{2}$ for deep-level impurities in silicon. ${ }^{3}$ Recently, however, single-crystal silicon doped with deep-level impurities to supersaturated concentrations - several orders of magnitude higher than the maximum equilibrium solubility limit - has been achieved using ion implantation and nanosecond pulsed laser melting (PLM), and extrinsic photoconductivity has been reported up to $110 \mathrm{~K}$ in vandium-supersatured silicon, ${ }^{11}$ and up to room-temperature in gold-supersaturated silicon. ${ }^{12}$ 
Silicon supersatured with chalcogens ( $\mathrm{S}, \mathrm{Se}$, or $\mathrm{Te}$ ) has been of particular interested because this material exhibits broadband absorption out to $\lambda=3100 \mathrm{~nm}(0.4 \mathrm{eV})$ with an absorption coefficient $\alpha \sim 10^{4} \mathrm{~cm}^{-1},{ }^{13-15}$ the highest ever reported for silicon in this wavelength range, comparable to the intrinsic absorption coefficient of Ge and $\operatorname{In}_{0.53} \mathrm{Ga}_{0.47} \mathrm{As},{ }^{16}$ and at least 12 orders of magnitude higher than that for un-doped silicon $\left(\alpha<10^{-8} \mathrm{~cm}^{-1}\right.$ for $\lambda>1550 \mathrm{~nm}) .{ }^{17}$ Despite this enhanced infrared absorption, photodiodes fabricated with chalcogen-supersaturated single crystal silicon have demonstrated only slightly extended photoresponse (to $1250 \mathrm{~nm}$ or $\approx 0.99 \mathrm{eV})^{18}$, and photoconductivity in the SWIR regime has been observed only at low temperature. ${ }^{14}$ Density functional theory (DFT) calculations of the electronic band structure indicate that the enhanced absorption is a result of extrinsic optical transitions involving a dopant-induced impurity band (IB) with a bandwidth of $\sim 100 \mathrm{meV}$ located within the silicon band gap. ${ }^{19-21}$ Due to the significant bandwidth, thermal ionization from the deep IB can overwhelm the extrinsic photoresponse.

Sanchez et al. ${ }^{19}$ proposed that co-doping the chalcogen donors with group III acceptors ( $\mathrm{B}, \mathrm{Al})$ could be used to control the location of the Fermi level within the IB. Increasing the amount of compensation (acceptor-to-donor ratio) increases the energetic gap between the Fermi level and the conduction band, thereby minimizing thermal ionization of carriers. Elliott et al. ${ }^{22}$ proposed such counterdoping with deep level donors and shallow acceptors to produce extrinsic silicon infrared detectors with high operating temperatures. Here, we present experimental verification of these proposals. We fabricated silicon co-doped to $\sim$ $0.2 \%$ atomic with sulfur and boron, and we show that it is possible to control the Fermi level location by tuning the boron-to-sulfur dopant ratio. Most importantly, we demonstrate that by simply tuning the Fermi level, it is possible to increase the photoresponse by three orders of magnitude, demonstrating, for the first time, the potential of chalcogen-supersaturated silicon for room-temperature infrared detection.

\section{MATERIAL FABRICATION}

Dopant compensation by co-doping requires precise matching of the impurity distribution for two different elements. This requirement is especially difficult to achieve for the two elements considered here, boron and sulfur, because both their equilibrium solubility and their diffusivity in solid silicon differ by several orders of magnitude. ${ }^{23}$ Nevertheless, with 
the predictability and control of ion implantation and PLM we were able to match the sulfur and boron concentration-depth profiles quite well, and to achieve the supersaturated concentrations of sulfur necessary to produce a strong absorption coefficient for sub-band gap wavelengths.

We fabricated a series of co-doped samples with a range of compensations by varying the boron concentration. All samples were double-side polished $p$-type, $10-30 \Omega$ cm resistivity, $\mathrm{Si}(001)$ wafers $775 \mu \mathrm{m}$ thick, and all received the same ${ }^{32} \mathrm{~S}^{+}$ion implant at $95 \mathrm{keV}$ to a dose of $3 \times 10^{15} \mathrm{~cm}^{-2}$. Following the sulfur implant, the samples received separate ${ }^{11} \mathrm{~B}^{+}$implants at $25 \mathrm{keV}$ to doses ranging from $3 \times 10^{13}$ to $1 \times 10^{16} \mathrm{~cm}^{-2}$. The implants were performed at room temperature with the substrates at a $7^{\circ}$ tilt relative to the incident beam. The doped surface layer was amorphized by the implants, and crystallinity was reestablished by PLM with four consecutive pulses from a spatially homogenized XeCl excimer laser (308 nm, 25 ns duration full width at half maximum, $\sim 2 \times 2 \mathrm{~mm}$ spot size). The laser pulses had fluences of $1.7 \mathrm{~J} / \mathrm{cm}^{2}$ for the first three pulses and $1.8 \mathrm{~J} / \mathrm{cm}^{2}$ for the final pulse, which melted the surface of the wafer to a depth of approximately $375 \mathrm{~nm}$. Further details on the fabrication of single crystal silicon supersaturated with sulfur by PLM have been described in detail previously, ${ }^{13,24-27}$ but the results presented here are the first demonstration of co-doping in supersaturated silicon.

Dopant concentration profiles were measured using secondary ion mass spectrometry (SIMS) with a Physical Electronics 6650 Dynamic SIMS instrument with a $6 \mathrm{keV}$ Cs ion beam. Fig. 1(a) and (b) show the dopant profiles and associated simulation curves after ion implantation and after PLM for sulfur (a) and for boron (b). The dopant profiles after implantation agree well with the predicted curves simulated by Stopping and Range of Ions in Matter (SRIM) software.

The shape of the sulfur and boron concentration profiles evolve during PLM as a result of dopant diffusion. This evolution is well understood and can be simulated for each dopant with three parameters: the liquid diffusivity $\left(D_{\text {liq }}\right)$, the diffusive velocity $\left(v_{\mathrm{D}}\right)$, and the equilibrium partition coefficient $\left(k_{\mathrm{eq}}\right) \cdot{ }^{13,28}$ Using literature values for $k_{\mathrm{eq}}\left(10^{-5}\right.$ for sulfur ${ }^{29}$ and 0.79 for boron $^{30}$ ) the simulations were best matched to the SIMS data with $D_{\text {liq }}=$ $2.5 \times 10^{-4} \mathrm{~cm}^{2} / \mathrm{s}$ and $v_{\mathrm{D}}=1 \mathrm{~m} / \mathrm{s}$ for sulfur and $D_{\text {liq }}=5 \times 10^{-4} \mathrm{~cm}^{2} / \mathrm{s}$ and $v_{\mathrm{D}}=0.9 \mathrm{~m} / \mathrm{s}$ for boron. These parameters are in good agreement with previous reports, ${ }^{13,31,32}$ which indicates that interactions between the boron and sulfur are minimal and do not significantly impact 


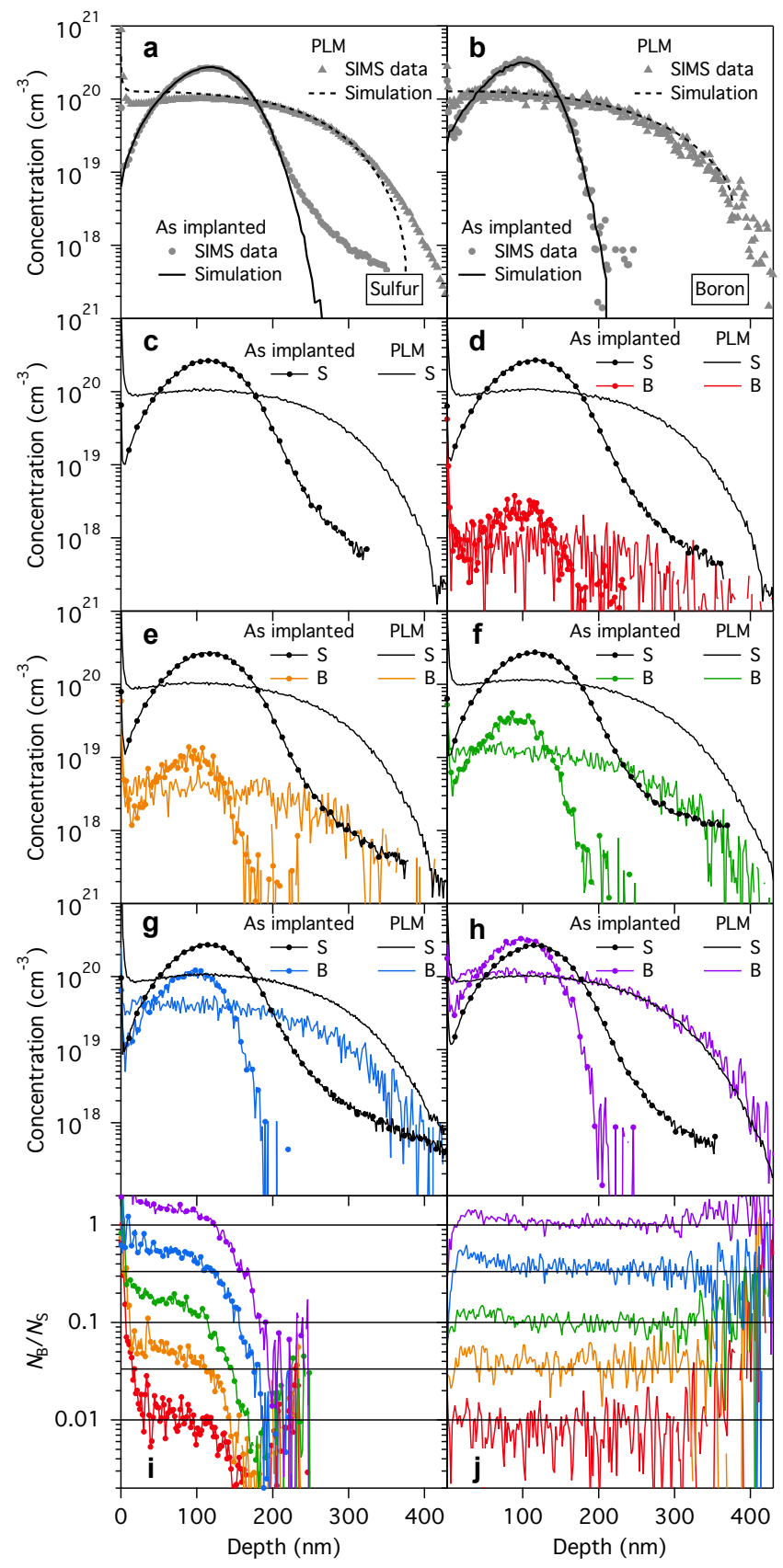

FIG. 1. (a),(b) Simulation and SIMS data of the dopant distribution after ion implantation and after PLM for sulfur (a) and boron (b) for a sample that received a $3 \times 10^{15} \mathrm{~cm}^{-2}$ dose for each element. (c)-(h) SIMS data of the sulfur and boron concentration profiles for 6 different samples following ion implantation (line and marker) and following PLM (line). All samples received the same $3 \times 10^{15} \mathrm{~cm}^{-2}$ sulfur implantation dose. The boron doses and corresponding boron-tosulfur ratios are (c) $0 \mathrm{~cm}^{-2}, \mathrm{~N}_{\mathrm{B}} / \mathrm{N}_{\mathrm{S}}=0$, (d) $3 \times 10^{13} \mathrm{~cm}^{-2}, \mathrm{~N}_{\mathrm{B}} / \mathrm{N}_{\mathrm{S}}=0.01$, (e) $1 \times 10^{14} \mathrm{~cm}^{-2}$, $\mathrm{N}_{\mathrm{B}} / \mathrm{N}_{\mathrm{S}}=0.03$, (f) $3 \times 10^{14} \mathrm{~cm}^{-2}, \mathrm{~N}_{\mathrm{B}} / \mathrm{N}_{\mathrm{S}}=0.1,(\mathrm{~g}) 1 \times 10^{15} \mathrm{~cm}^{-2}, \mathrm{~N}_{\mathrm{B}} / \mathrm{N}_{\mathrm{S}}=0.33$, and (h) $3 \times 10^{15} \mathrm{~cm}^{-2}, \mathrm{~N}_{\mathrm{B}} / \mathrm{N}_{\mathrm{S}}=1$. (i),(j) Ratio of the boron-to-sulfur concentration profiles following ion implantation (i) and following PLM (j). 
dopant redistribution during PLM. The simulation results, shown in Fig. 1(a) and (b), agree well with the SIMS data, but they differ slightly at the near-surface region because the effects of dopant evaporation were not included, and at the deepest portion of the curves likely because of knock-on effects during SIMS analysis.

In effort to match the sulfur and boron dopant profiles after PLM, we tried 3 different boron implantation energies (not shown). We found good agreement with the $25 \mathrm{keV}$ energy used here, which produces an $\sim 100 \mathrm{~nm}$ average ion projected range for boron, slightly shallower than the $\sim 120 \mathrm{~nm}$ range for sulfur implanted at $95 \mathrm{keV}$. The shallower boron implant likely accommodates for its slightly faster diffusion, and the result is that the boron and sulfur profiles are very nearly equalized after PLM. Fig. 1(c)-(h) show the sulfur and boron concentration profiles following ion implantation and following PLM for 6 different samples implanted with increasing boron doses. To clearly illustrate the match of the dopant profiles, the boron-to-sulfur concentration ratio, $\mathrm{N}_{\mathrm{B}} / \mathrm{N}_{\mathrm{S}}$ for each of the 5 samples in Fig. 1(d)(h) are shown in Fig. 1(i) (after ion implantation) and Fig. 1(j) (after PLM). Critically, after PLM, $\mathrm{N}_{\mathrm{B}} / \mathrm{N}_{\mathrm{S}}$ is essentially constant throughout the thickness of doped layer, and it is equal to the ratio of the implanted doses. For the remainder of the manuscript, we identify samples by their $\mathrm{N}_{\mathrm{B}} / \mathrm{N}_{\mathrm{S}}$ value. In total, we report measurements on co-doped samples containing 13 different dopant ratios with $\mathrm{N}_{\mathrm{B}} / \mathrm{N}_{\mathrm{S}}$ ranging from 0.01 to 3.33. For reference, we also report measurements on uncompensated, sulfur-only material $\left(\mathrm{N}_{\mathrm{B}} / \mathrm{N}_{\mathrm{S}}=0\right)$, and the un-implanted silicon substrate ("Si control").

\section{ELECTRONIC PROPERTIES}

We performed room-temperature van der Pauw and Hall measurements on the co-doped sample series to confirm that the boron acceptors electrically compensate the sulfur donors. Cloverleaf device structures with a $1 \mathrm{~mm}$ diameter were lithographically defined from the PLM material following the fabrication procedure outlined in Ref. 27. Due to the varying dopant concentration throughout the depth of the hyperdoped layer (see Fig. 1), we analyze only the depth-averaged sheet resistance, $R_{\mathrm{s}}=1 / \int \sigma(z) d z$, and the sheet carrier concentration, $n_{\mathrm{s}}=\int n(z) d z$, where $\sigma(z)$ and $n(z)$ are the depth-dependent conductivity and carrier concentration. Fig. 2(a),(b), and (c) show $R_{\mathrm{s}}, n_{\mathrm{s}}$ and the carrier mobility $\mu=1 / e R_{\mathrm{s}} n_{\mathrm{s}}$, respectively, as a function of $\mathrm{N}_{\mathrm{B}} / \mathrm{N}_{\mathrm{S}}$. Each data point in Fig. 2 is the average for two nominally 


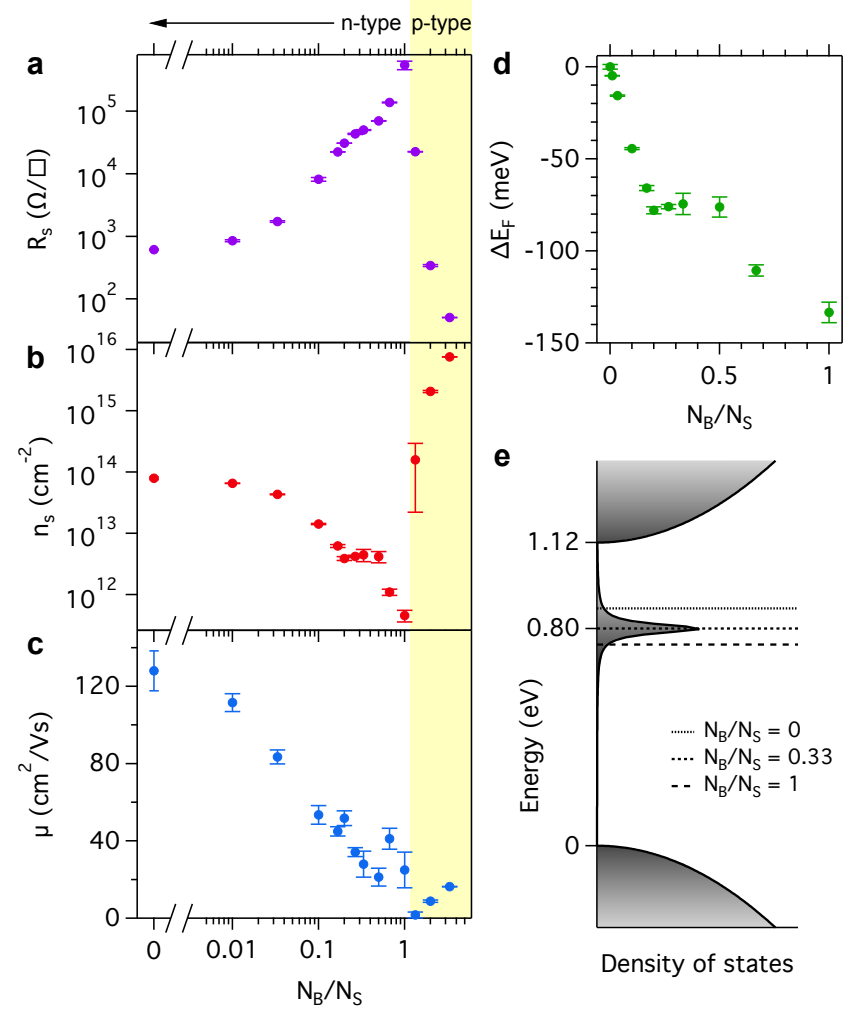

FIG. 2. Electronic properties of the co-doped sample series. (a) Sheet resistance $R_{\mathrm{s}}$ determined from van der Pauw measurements on a lithographically defined cloverleaf device structure. (b) Sheet carrier concentration $n_{\mathrm{s}}$ determined from Hall measurements with a maximum magnetic field of 1.5 T. (c) Carrier mobility calculated by $\mu=1 / e R_{\mathrm{s}} n_{\mathrm{s}}$. (d) Shift in the Fermi level $E_{F}$ calculated from the data in (b) and Eq. 1. (e) Density of states schematic illustrating the relative location of $E_{F}$ in the impurity band for three different compensation values.

identical samples, and the error bars give the spread in the measured values.

As expected for dopant compensation, as $\mathrm{N}_{\mathrm{B}} / \mathrm{N}_{\mathrm{S}}$ increases from 0 to $1, R_{\mathrm{s}}$ increases and $n_{\mathrm{s}}$ decreases. However, above $\mathrm{N}_{\mathrm{B}} / \mathrm{N}_{\mathrm{S}}=1$, these trends invert. This inversion occurs simultaneously with a change in the majority carrier type as determined by a change in the direction of the Hall slope. Material with $\mathrm{N}_{\mathrm{B}} / \mathrm{N}_{\mathrm{S}} \leq 1$ is $n$-type, while above $\mathrm{N}_{\mathrm{B}} / \mathrm{N}_{\mathrm{S}}=1$, the material is over-compensated and it becomes $p$-type. For the remainder of the manuscript, we focus only on samples for which $\mathrm{N}_{\mathrm{B}} / \mathrm{N}_{\mathrm{S}} \leq 1$.

We can calculate the relative change in the Fermi level $E_{F}$ due to the boron compensation using the data in Fig. 2(b) and Boltzmann statistics ${ }^{33}$

$$
\Delta E_{F}=E_{F}\left(\mathrm{~N}_{\mathrm{B}} / \mathrm{N}_{\mathrm{S}}=x\right)-E_{F}\left(\mathrm{~N}_{\mathrm{B}} / \mathrm{N}_{\mathrm{S}}=0\right)
$$




$$
=k_{B} T\left[\ln \left(n_{\mathrm{s}}\left(\mathrm{N}_{\mathrm{B}} / \mathrm{N}_{\mathrm{S}}=x\right)\right)-\ln \left(n_{\mathrm{s}}\left(\mathrm{N}_{\mathrm{B}} / \mathrm{N}_{\mathrm{S}}=0\right)\right)\right]
$$

where $k_{B}$ is the Boltzmann constant and $T$ is the temperature. Fig. $2(\mathrm{~d})$ plots $\Delta E_{F}$ as a function of $\mathrm{N}_{\mathrm{B}} / \mathrm{N}_{\mathrm{S}}$. The DFT results of Ref. 19 predicted that the Fermi level $E_{F}$ would be near the top of the IB for sulfur-only doping $\left(\mathrm{N}_{\mathrm{B}} / \mathrm{N}_{\mathrm{S}}=0\right)$, and that the addition of boron

would lower the Fermi level $E_{F}$ toward the center of the IB. The results in Fig. 2(d) are consistent with this prediction. Assuming that the boron is all electrically active, the rate of change of $\Delta E_{F}$ with compensation in Fig. 2(d) provides insight to the density of states (DOS) at $E_{F}$. We interpret the plateau near $\sim \mathrm{N}_{\mathrm{B}} / \mathrm{N}_{\mathrm{S}}=0.3$ as the compensation value for which $E_{F}$ is located at the center region of the IB with the highest DOS, because at this point, $E_{F}$ is essentially pinned even as additional compensation is introduced.

A schematic of the DOS, informed by the known ionization energy for sulfur dopants in Si $(320 \mathrm{meV})^{34}$ and the DFT results in Ref. 19 and 21, is presented in Fig. 2(e). The horizontal lines indicate the location of $E_{F}$ for three different compensation values. Following from the plateau in Fig. 2(d), we positioned $E_{F}$ in the middle of the IB (half-filled occupation) for $\mathrm{N}_{\mathrm{B}} / \mathrm{N}_{\mathrm{S}}=0.33$, and indicate the relative locations of $E_{F}$ for $\mathrm{N}_{\mathrm{B}} / \mathrm{N}_{\mathrm{S}}=0$ and $\mathrm{N}_{\mathrm{B}} / \mathrm{N}_{\mathrm{S}}=1$ using their corresponding values of $\Delta E_{F}$.

\section{OPTICAL ABSORPTION}

Optical absorption measurements provide further verification that boron compensation moves the Fermi level within IB. We measured the transmittance $(T)$ and reflectance $(R)$ of the co-doped series using a PerkinElmer Lambda $950 \mathrm{UV} / \mathrm{Vis} / \mathrm{NIR}$ Spectrometer for photon energies 0.7 to $1.4 \mathrm{eV}(\lambda=1.77$ to $0.89 \mu \mathrm{m})$ and a PerkinElmer Spectrum 400 FTIR Spectrometer for photon energies 0.05 to $0.9 \mathrm{eV}(\lambda=25$ to $1.38 \mu \mathrm{m})$. For both instruments, the illumination spot was apertured so as to probe only the laser melted area. A silver mirror was used as a $100 \%$ reflectance standard for the UV/Vis/NIR data and a gold mirror was used for the FTIR data. Five nominally identical samples were measured for every doping condition, and the absorptance, $A$, shown in Fig. 3(a), was calculated by $A=1-\bar{T}-\bar{R}$, where $\bar{T}$ and $\bar{R}$ are the average of the 5 measurements. The absorptance of the silicon substrate is also shown for reference. There is an overlap region for the data acquired from the two different spectrometers for photon energies 0.7 to $0.9 \mathrm{eV}$. Due to slight 

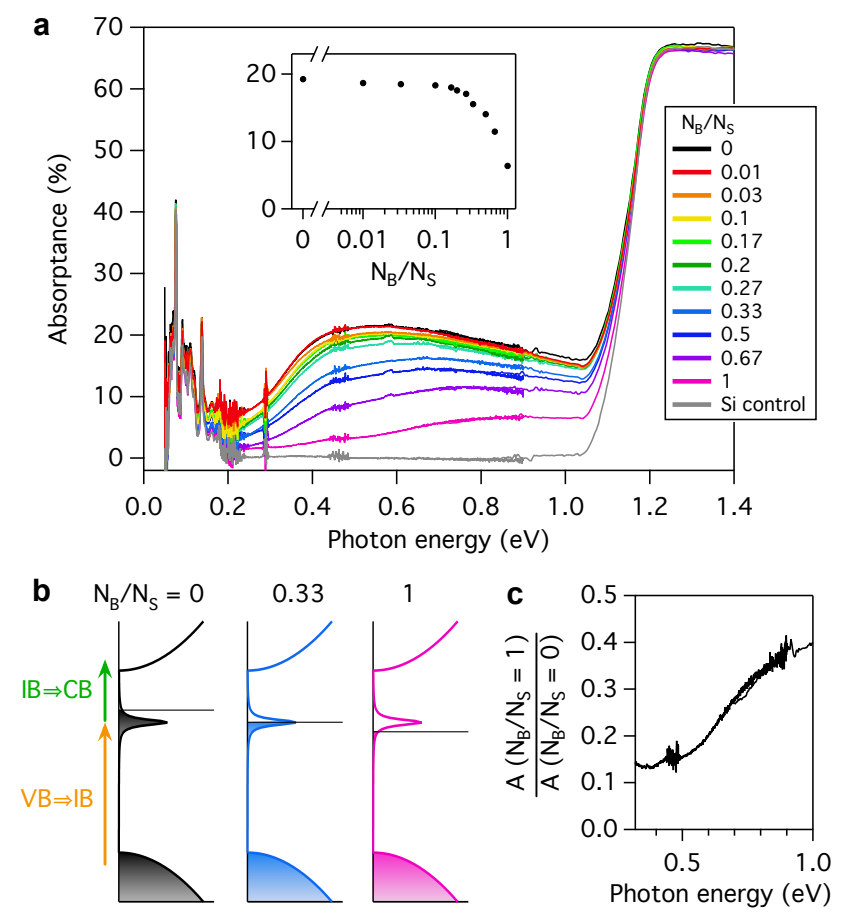

FIG. 3. (a) Optical absorptance spectra for the co-doped sample series with $\mathrm{N}_{\mathrm{B}} / \mathrm{N}_{\mathrm{S}}$ ranging from 0 to 1. Inset: Absorptance at $0.8 \mathrm{eV}(\lambda=1550 \mathrm{~nm})$ as a function of $\mathrm{N}_{\mathrm{B}} / \mathrm{N}_{\mathrm{S}}$, illustrating the drop in absorptance for $\mathrm{N}_{\mathrm{B}} / \mathrm{N}_{\mathrm{S}}>0.1$. (b) Schematic of the density of states occupation for three different values of $\mathrm{N}_{\mathrm{B}} / \mathrm{N}_{\mathrm{S}}$. The horizontal lines indicate the relative location of $E_{F}$. For simplicity, the schematic is drawn as if at zero temperature, with a step function Fermi-Dirac distribution. (c) Ratio of the sub-band gap absorptance for the 1-to-1 dopant ratio $\left(\mathrm{N}_{\mathrm{B}} / \mathrm{N}_{\mathrm{S}}=1\right)$ to that for no compensation $\left(\mathrm{N}_{\mathrm{B}} / \mathrm{N}_{\mathrm{S}}=0\right)$.

calibration offsets for the two instruments, the FTIR curves were rigidly shifted such that they aligned with the UV/Vis/NIR curves at $0.8 \mathrm{eV}$. This shift was less than $1 \%$ absolute on average, and the agreement of the spectral shape in the overlap region from the two different spectrometers is very good for all samples.

Consistent with previous reports, ${ }^{14,15}$ the uncompensated, sulfur-only control $\left(\mathrm{N}_{\mathrm{B}} / \mathrm{N}_{\mathrm{S}}=\right.$ 0) exhibits enhanced broadband infrared absorptance down to $0.3 \mathrm{eV}$ that is not present in the silicon substrate. The increase in absorptance below $0.2 \mathrm{eV}$ present in all samples is most likely due to oxygen and carbon impurities in the silicon substrate. ${ }^{35-37}$ Increasing dopant compensation (increasing $\mathrm{N}_{\mathrm{B}} / \mathrm{N}_{\mathrm{S}}$ ), results in a monotonic decrease in the infrared absorptance. This effect is illustrated explicitly in the inset to Fig. 3(a) for $0.8 \mathrm{eV}$ photon 
energy $(\lambda=1550 \mathrm{~nm})$.

Fig. 3(b) provides a schematic of the DOS and $E_{F}$ for three $\mathrm{N}_{\mathrm{B}} / \mathrm{N}_{\mathrm{S}}$ values, with shading to indicate state occupation, and arrows to indicate potential optical transitions to and from the IB (originating from the valance band, VB, and transitioning to the conduction band, $\mathrm{CB}$, respectively). If the IB is full for $\mathrm{N}_{\mathrm{B}} / \mathrm{N}_{\mathrm{S}}=0$, as predicted by Ref. 19, 21 and illustrated in Fig. 3(b), then introducing compensation has two simultaneous effects on the optical absorption: the number of states available for IB $\rightarrow \mathrm{CB}$ decreases, but the number of states available for $\mathrm{VB} \rightarrow \mathrm{IB}$ increases. Therefore, depending on the relative strength of these different optical transitions, the infrared absorptance could have increased or decreased with compensation. Ref. 19 calculated the absorption coefficient for $\mathrm{N}_{\mathrm{B}} / \mathrm{N}_{\mathrm{S}}=0$ and $\mathrm{N}_{\mathrm{B}} / \mathrm{N}_{\mathrm{S}}=1$, and, their results are consistent with the observations presented here. They investigated the relative strength of the two optical transitions by comparing the imaginary part of the dielectric function and confirmed that $\mathrm{VB} \rightarrow \mathrm{IB}$ is significantly weaker than $\mathrm{IB} \rightarrow \mathrm{CB}$.

If there were no energetic broadening of the impurity band, the VB-IB and IB-CB band gaps would be $0.8 \mathrm{eV}$ and $0.32 \mathrm{eV}$, respectively. Because larger energy photons can drive either $\mathrm{VB} \rightarrow \mathrm{IB}$ or $\mathrm{IB} \rightarrow \mathrm{CB}$ transitions, while those with smaller energies can only drive $\mathrm{IB} \rightarrow \mathrm{CB}$ transitions, we expect a spectral dependence to the decrease in absorptance with increasing compensation. To highlight the spectral change, Fig. 3(c) shows the ratio of the absorptance for $\mathrm{N}_{\mathrm{B}} / \mathrm{N}_{\mathrm{S}}=1$ to that for $\mathrm{N}_{\mathrm{B}} / \mathrm{N}_{\mathrm{S}}=0$ for the sub-band gap photon energy range $(0.3$ to $1.0 \mathrm{eV})$. In agreement with expectations, the data in Fig. 3(c) show a more substantial decrease in the absorption of photons with energies less than $\sim 0.8 \mathrm{eV}$. There is not a sharp cutoff at this energy, however, likely because at the sulfur concentrations considered here $(\sim 0.2 \%$ atomic), the impurity band is predicted to have a bandwidth on the order of $100 \mathrm{meV},{ }^{19-21}$ which is supported by the experimental data in Fig. 2(d).

\section{INFRARED PHOTORESPONSE}

We performed photoconductivity measurements on select samples to determine the effect of dopant compensation on the infrared photoresponse. The experimental setup is diagrammed in Fig. 4(a). Photolithography and $\mathrm{SF}_{6}$-based reactive ion etching to a depth of $1 \mu \mathrm{m}$ were used to define a $1 \times 1.28 \mathrm{~mm}^{2}$ rectangular device area from the PLM material. A pair of rectangular metal contacts (Ti/Au stack, 30/160 nm thickness, $0.14 \times 1 \mathrm{~mm}^{2}$ area) 
were then deposited on opposite sides of the device, leaving exposed a square $1 \times 1 \mathrm{~mm}^{2}$ active area. The device contacts were connected in series with a Keithley 2400 DC voltage source $\left(V_{\mathrm{a}}\right)$ and a load resistor of known resistance $\left(R_{\mathrm{L}}\right)$. The center of the device was illuminated by $21 \mathrm{~mW}$ of optical power from a $\lambda=1550 \mathrm{~nm}$ laser diode mechanically chopped at $839 \mathrm{~Hz}$ and focused to a $\sim 700 \mu \mathrm{m}$ diameter spot size. During illumination, the sample resistance is reduced due to an increase in the sheet carrier concentration by $\Delta n_{\mathrm{s}}$ as a result of impurity photoionization. This change in sample resistance was detected as an increase in the voltage across $R_{\mathrm{L}}$. The magnitude of the voltage change $(\Delta V)$ across $R_{\mathrm{L}}$ was measured by a Signal Recovery 7265 lock-in amplifier and scaled by $\frac{\pi}{\sqrt{2}}$ to convert the RMS value of the first Fourier component to the peak-to-peak amplitude of the square wave voltage change. $\Delta V$ is related to the change in sample resistance $\Delta R$ by:

$$
\frac{\Delta V}{V_{\mathrm{a}}}=\frac{R_{\mathrm{L}}}{R_{\mathrm{avg}}+\frac{\Delta R}{2}+R_{\mathrm{L}}}-\frac{R_{\mathrm{L}}}{R_{\mathrm{avg}}-\frac{\Delta R}{2}+R_{\mathrm{L}}},
$$

where $R_{\text {avg }}$ is the time-averaged sample resistance.

Fig. 4(b) shows $\Delta V$ as a function of the applied bias for 6 different samples: 4 codoped samples with different values of $\mathrm{N}_{\mathrm{B}} / \mathrm{N}_{\mathrm{S}}$, an uncompensated $\mathrm{N}_{\mathrm{B}} / \mathrm{N}_{\mathrm{S}}=0$ sample, and a plain silicon control. As expected from Eq. 2, there is a linear increase in $\Delta V$ with $V_{\text {a }}$ for all samples except the silicon control, which produced no measurable response. The magnitude of the $\Delta V / V_{\mathrm{a}}$ slope is found to increase with $\mathrm{N}_{\mathrm{B}} / \mathrm{N}_{\mathrm{S}}$ (Fig. 4(c)). The magnitude of $\Delta V / V_{\mathrm{a}}$, however, depends on the experimentally chosen value of $R_{\mathrm{L}}$, and it is maximized when $R_{\mathrm{L}}=R_{\text {avg }}$. Because the resistivity of the different samples varies by several orders of magnitude (Fig. 2(a)), for each measurement the value of $R_{\mathrm{L}}$ was chosen to closely match $R_{\text {avg }}$ (see Table I). We calculated $\Delta R$ for each sample using Eq. 2 and the values of $R_{\mathrm{L}}$, $R_{\mathrm{avg}}$, and $\Delta V / V_{\mathrm{a}}$. The results are listed in Table I. The value of $\Delta R$ for the silicon control is an upper bound based on the noise limit of the measurement.

The fractional change in sample resistance $\Delta R / R_{\text {avg }}$ and the $\Delta R$ photoresponse increase with compensation. This improvement can be explained by the reduced background carrier concentration (Fig. 2(b)). Assuming uniform photoresponse across the device area,

$$
\Delta R=A\left(\frac{1}{e \mu_{\mathrm{d}} n_{\mathrm{s}}}-\frac{1}{e \mu_{\mathrm{i}}\left(n_{\mathrm{s}}+\Delta n_{\mathrm{s}}\right)}\right),
$$

where $A$ is a geometrical constant, $e$ is the electron charge, $\mu_{\mathrm{d}(\mathrm{i})}$ is the carrier mobility when the sample is dark (illuminated), $n_{\mathrm{s}}$ is the sheet carrier concentration in the dark and $\Delta n_{\mathrm{s}}$ 

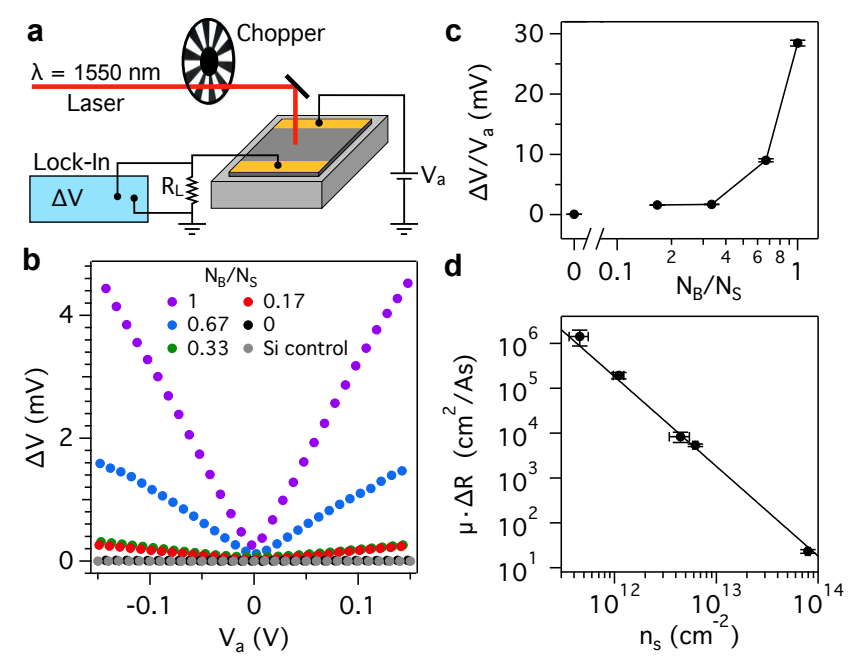

FIG. 4. Counterclockwise from top left: (a) Experimental setup for photoconductivity measurements. The active area of the device is shown in gray and the two rectangular metal contacts are shown in yellow. The device is illuminated by a mechanically chopped $\lambda=1550 \mathrm{~nm}$ laser diode. The laser diode optical power was determined using a NIST calibrated germanium photodiode. (b) Lock-in voltage measured across $R_{\mathrm{L}}$ as a function of the applied DC bias $\left(V_{\mathrm{a}}\right)$ for 6 different samples. (c) The slopes of $\Delta V$ vs. $V_{\text {a }}$ extracted from (b). (d) The product of the carrier mobility (Fig. 2(c)) and $\Delta R$ (determined from $\Delta V / V_{\text {a }}$ using Eq. 2), plotted as a function of the sheet carrier concentration (Fig. 2(b)).

is the photogenerated sheet carrier concentration. If $\mu_{\mathrm{i}}=\mu_{\mathrm{d}}=\mu$, then

$$
\mu \cdot \Delta R=\frac{A}{e}\left(\frac{\Delta n_{\mathrm{s}}}{n_{\mathrm{s}}^{2}+\left(\Delta n_{\mathrm{s}}\right) n_{\mathrm{s}}}\right),
$$

and in the limit $\Delta n_{\mathrm{s}} \ll n_{\mathrm{s}}$,

$$
\mu \cdot \Delta R=\frac{A}{e}\left(\frac{\Delta n_{\mathrm{s}}}{n_{\mathrm{s}}^{2}}\right) .
$$

Fig. 4(d) shows the mobility- $\Delta R$ product for each sample as a function of its sheet carrier concentration. The line is a fit using Eq. 5 with a single fit constant $C=A \Delta n_{\mathrm{s}} / e$. The quality of the fit implies that $\Delta n_{\mathrm{s}} \approx$ constant, and demonstrates that the improvement in the $\Delta R$ photoresponse is due almost entirely to the reduction in $n_{\mathrm{s}}$ achieved by compensation.

Considering the smaller absorptance at $1550 \mathrm{~nm}$ for samples with increased compensation (Fig. 3(a) Inset), it is surprising that the data in Fig. 4(d) are well fit assuming a constant value of $\Delta n_{\mathrm{s}}$. Rather, we would have expected a corresponding reduction in $\Delta n_{\mathrm{s}}$ for larger values of $\mathrm{N}_{\mathrm{B}} / \mathrm{N}_{\mathrm{S}}$. One potential explanation is that there is an improvement in carrier 


\begin{tabular}{cccc}
\hline \hline $\mathrm{N}_{\mathrm{B}} / \mathrm{N}_{\mathrm{S}}$ & $R_{\text {avg }}(\Omega)$ & $R_{\mathrm{L}}(\Omega)$ & $\Delta R(\Omega)$ \\
\hline Si control & $1.63 \times 10^{3}$ & $1.67 \times 10^{3}$ & $<2.6 \times 10^{-2}$ \\
0 & $6.34 \times 10^{2}$ & $6.20 \times 10^{2}$ & $(1.81 \pm 0.03) \times 10^{-1}$ \\
0.17 & $1.85 \times 10^{4}$ & $1.99 \times 10^{4}$ & $(1.20 \pm 0.02) \times 10^{2}$ \\
0.33 & $4.28 \times 10^{4}$ & $5.07 \times 10^{4}$ & $(2.97 \pm 0.05) \times 10^{2}$ \\
0.67 & $1.30 \times 10^{5}$ & $1.20 \times 10^{5}$ & $(4.7 \pm 0.1) \times 10^{3}$ \\
1 & $4.98 \times 10^{5}$ & $5.09 \times 10^{5}$ & $(5.7 \pm 0.1) \times 10^{4}$ \\
\hline \hline
\end{tabular}

TABLE I. Photoconductivity measurement experimental parameters and results.

mobility under illumination for compensated samples. If $\mu_{\mathrm{i}} / \mu_{\mathrm{d}}=x$, then Eq. 5 becomes:

$$
\mu_{\mathrm{d}} \cdot \Delta R=\frac{A}{e}\left(\frac{\Delta n_{\mathrm{s}}+n_{\mathrm{s}}\left(1-\frac{1}{x}\right)}{n_{\mathrm{s}}^{2}}\right) .
$$

Thus, if $\mu_{\mathrm{i}}>\mu_{\mathrm{d}}$, it is analogous to an enhancement in $\Delta n_{\mathrm{s}}$ by the factor $n_{\mathrm{s}}\left(1-\frac{1}{x}\right)$. Since the $E_{C}-E_{F}$ gap grows with compensation and is at least $\sim 6$ times larger than $k_{B} T$ at room temperature for $\mathrm{N}_{\mathrm{B}} / \mathrm{N}_{\mathrm{S}}=1$ (from Fig. $2(\mathrm{~d}) E_{C}-E_{F} \approx 150 \mathrm{meV}$ or larger), it is likely that conduction in the dark occurs within the IB rather than by thermal excitation to the CB. Alternatively, upon illumination, conduction likely occurs via photoexcited carriers in the CB. Since conduction within an IB is typically associated with a lower carrier mobility ${ }^{38,39}$, this phenomenon could result in $\mu_{\mathrm{i}}>\mu_{\mathrm{d}}$ for the compensated samples.

The room-temperature electrical detection of carriers photogenerated with sub-band gap radiation demonstrated here is crucial for the development of silicon-based infrared photodetectors. Until now, the potential of extrinsic photodetectors based on highly absorbing sulfur-supersaturated silicon has been hindered by thermal carrier generation resulting in a high dark $n_{\mathrm{s}}$. By controlling the dopant compensation, we were able to tune the Fermi level location within the impurity band and therefore reduce $n_{\mathrm{s}}$ and achieve an increase in $\Delta R / R_{\text {avg }}$ by about three orders of magnitude. Optimization of the photoconductor device architecture including surface passivation, light management for improved absorption, and contact geometry for improved carrier collection, along with optimization of the dopant compensation balance provide opportunities for further improvement in photoresponse and a path toward room-temperature broadband operation of silicon detectors at sub-band gap 
wavelengths.

\section{ACKNOWLEDGEMENTS}

We thank Jacob J. Krich, Mark T. Winkler, Joseph T. Sullivan, Jeffrey M. Warrender, Jay Mathews and Peter D. Persans for useful discussions. Research at MIT was supported by in part by the MIT-KFUPM Center for Clean Water and Energy; the National Science Foundation grant for Energy, Power, and Adaptive Systems under Contract No. ECCS-1102050; and the National Science Foundation (NSF) and the Department of Energy (DOE) under NSF CA No. EEC-1041895. Research at Harvard was supported by the U.S. Army Research Office under Contract No. W911NF-12-1-0196 and the U.S. Army-ARDEC under Contract No. W15QKN-07-P-0092. This work was performed in part at the Center for Nanoscale Systems (CNS), a member of the National Nanotechnology Infrastructure Network (NNIN), which is supported by the National Science Foundation under NSF award no. ECS-0335765.

1 A. Rogalski, Progress in Quantum Electronics, 27, 59 (2003).

2 M. Casalino, G. Coppola, M. Iodice, I. Rendina, and L. Sirleto, Sensors, 10, 10571 (2010).

3 N. Sclar, Progress in Quantum Electronics, 9, 149 (1984).

4 H. Y. Fan and A. K. Ramdas, Journal Of Applied Physics, 30, 1127 (1959).

5 J. D. B. Bradley, P. E. Jessop, and A. P. Knights, Applied Physics Letters, 86, 241103 (2005).

6 A. P. Knights, J. D. B. Bradley, S. H. Gou, and P. E. Jessop, Journal of Vacuum Science \& Technology A: Vacuum, Surfaces, and Films, 24, 783 (2006).

7 M. W. Geis, S. J. Spector, M. E. Grein, R. J. Schulein, J. U. Yoon, D. M. Lennon, C. M. Wynn, S. T. Palmacci, F. Gan, F. X. Käertner, and T. M. Lyszczarz, Optics Express, 15, 16886 (2007).

8 S. Park, K. Yamada, T. Tsuchizawa, T. Watanabe, H. Nishi, H. Shinojima, and S.-i. Itabashi, Optics Express, 18, 15303 (2010).

9 N. Sclar, Infrared Physics, 17, 71 (1977).

10 R. Hull, Properties of Crystalline Silicon (INSPEC, London, 1999). 
11 E. Garcia-Hemme, R. Garcia-Hernansanz, J. Olea, D. Pastor, A. Del Prado, I. Mártil, and G. Gonzalez-Diaz, Applied Physics Letters, 103, 032101 (2013).

12 J. P. Mailoa, A. J. Akey, C. B. Simmons, D. Hutchinson, J. Mathews, J. T. Sullivan, D. Recht, M. T. Winkler, J. S. Williams, J. M. Warrender, P. D. Persans, M. J. Aziz, and T. Buonassisi, "Room-temperature sub-band gap optoelectronic response of hyperdoped silicon," (2013), submitted for publication.

13 B. P. Bob, A. Kohno, S. Charnvanichborikarn, J. M. Warrender, I. Umezu, M. Tabbal, J. S. Williams, and M. J. Aziz, Journal Of Applied Physics, 107, 123506 (2010).

14 J. T. Sullivan, C. B. Simmons, J. J. Krich, A. J. Akey, D. Recht, M. J. Aziz, and T. Buonassisi, Journal Of Applied Physics, 114, 103701 (2013).

15 I. Umezu, J. M. Warrender, S. Charnvanichborikarn, A. Kohno, J. S. Williams, M. Tabbal, D. G. Papazoglou, X.-C. Zhang, and M. J. Aziz, Journal Of Applied Physics, 113, 213501 (2013).

16 S. Adachi, Optical Constants of Crystalline and Amorphous Semiconductors, Numerical Data and Graphical Information (Kluwer Academic Publisher, Norwell, 1999).

17 M. A. Green and M. J. Keevers, Progress in Photovoltaics: Research and Applications, 3, 189 (1995).

18 A. J. Said, D. Recht, J. T. Sullivan, J. M. Warrender, T. Buonassisi, P. D. Persans, and M. J. Aziz, Applied Physics Letters, 99, 073503 (2011).

19 K. Sanchez, I. Aguilera, P. Palacios, and P. Wahnon, Physical Review B, 82, 165201 (2010).

20 E. Ertekin, M. T. Winkler, D. Recht, A. J. Said, M. J. Aziz, T. Buonassisi, and J. C. Grossman, Physical Review Letters, 108, 026401 (2012).

21 H. Shao, C. Liang, Z. Zhu, B.-Y. Ning, X. Dong, X.-J. Ning, L. Zhao, and J. Zhuang, Applied Physics Express, 6, 085801 (2013).

22 C. T. Elliott, P. Migliorato, and A. W. Vere, Infrared Physics, 18, 65 (1978).

23 P. Pichler, Intrinsic Point Defects, Impurities, and Their Diffusion in Silicon, edited by S. Selberherr (Springer Verlag, New York, 2004).

24 T. G. Kim, J. M. Warrender, and M. J. Aziz, Applied Physics Letters, 88, 241902 (2006).

25 M. Tabbal, T. Kim, J. M. Warrender, M. J. Aziz, B. L. Cardozo, and R. S. Goldman, Journal Of Vacuum Science \& Technology B, 25, 1847 (2007). 
26 S. H. Pan, D. Recht, S. Charnvanichborikarn, J. S. Williams, and M. J. Aziz, Applied Physics Letters, 98, (2011).

27 M. T. Winkler, D. Recht, M.-J. Sher, A. J. Said, E. Mazur, and M. J. Aziz, Physical Review Letters, 106, 178701 (2011).

28 D. Hoglund, M. Thompson, and M. Aziz, Physical Review B, 58, 189 (1998).

29 S. Fischler, Journal Of Applied Physics, 33, 1615 (1962).

30 R. N. Hall, Journal of Physical Chemistry, 57, 836 (1953).

31 D. Recht, J. T. Sullivan, R. Reedy, T. Buonassisi, and M. J. Aziz, Applied Physics Letters, 100, (2012).

32 S. Whelan, A. La Magna, V. Privitera, G. Mannino, M. Italia, C. Bongiorno, G. Fortunato, and L. Mariucci, Physical Review B, 67, 075201 (2003).

33 J. S. Blakemore, Semiconductor Statistics (Courier Dover Publications, 2002).

34 E. Janzen, R. Stedman, G. Grossmann, and H. G. Grimmeiss, Physical Review B, 29, 1907 (1984).

35 W. Kaiser, P. Keck, and C. Lange, Physical Review, 101, 1264 (1956).

36 R. C. Newman, Advances In Physics, 18, 545 (1969).

37 R. C. Newman and R. S. Smith, Journal Of Physics And Chemistry Of Solids, 30, 1493 (1969).

38 O. V. Emelianenko, T. S. Lagunova, D. N. Nasledov, and G. N. Talalakin, Soviet Physics-Solid State, 7, 1063 (1965).

39 J. Basinski and R. Olivier, Canadian Journal Of Physics, 45, 119 (1967). 